\title{
Estudo da imunopatogenia das lesões no sistema nervoso central de cães naturalmente acometidos por leishmaniose visceral
}

\author{
Study of the immunopathogenesis of central nervous system lesions in dogs naturally \\ affected by visceral leishmaniasis
}

\author{
Tatianna Frate SCHWARDT ${ }^{1}$; Juliana Peloi VIDES ${ }^{1}$; Eveline Tozzi BRAGA ${ }^{1}$; Acácio Duarte \\ PACHECO $^{1}$; Hélio LANGONI ${ }^{3}$; Diego GENEROSO ${ }^{3}$; Gisele Fabrino MACHADO ${ }^{1}$; Márcia Dalastra \\ LAURENTI $^{2}$; Mary MARCONDES ${ }^{1}$
}

\author{
${ }^{1}$ Faculdade de Medicina Veterinária da Universidade Estadual Paulista, Araçatuba-SP, Brasil \\ ${ }^{2}$ Departamento de Patologia da Faculdade de Medicina da Universidade de São Paulo, São Paulo-SP, Brasil \\ ${ }^{3}$ Faculdade de Medicina Veterinária da Universidade Estadual Paulista, Botucatu-SP, Brasil
}

\begin{abstract}
Resumo
A Leishmaniose visceral em cães é descrita como uma doença de caráter crônico na qual os principais sintomas são perda progressiva de peso, caquexia e lesões dermatológicas. Recentemente, a doença tem sido relacionada com alterações neurológicas. Um total de 40 cães portadores de leishmaniose visceral foi dividido em dois grupos. $\mathrm{O}$ primeiro composto por cães sem sintomas neurológicos $(n=30)$ e o segundo grupo composto por cães com sintomas neurológicos $(\mathrm{n}=10)$. Amostras de encéfalo foram coletadas e armazenadas em formalina tamponada, para realização de imunoistoquímica para a pesquisa de formas amastigotas de Leishmania (Leishmania) infantum chagasi, linfócitos T CD3+, CD4+ e CD8+ e macrófagos. A reação de imunoistoquímica não revelou formas amastigotas do parasita. Linfócitos T estavam presentes em 24/30 (80\%) dos cães sem sintomas neurológicos e em todos os cães do segundo grupo ( $\mathrm{p}=0,0011)$. Linfócitos CD4+ e CD8+ raramente foram observados, apresentando imunomarcação para CD4+ em 10/40 (25\%) dos cães e em metade dos animais do grupo neurológico $(\mathrm{p}=0,0090)$. A presença de CD8+ foi detectada em 4/10 (40\%) cães com doenças neurológicas ( $\mathrm{p}=0,0021)$. Macrófagos foram observados em 38/40 (95\%) cães, sem diferença estatística significante entre os dois grupos $(\mathrm{p}=0,7664)$.
\end{abstract}

Palavras-chave: TCD3+. TCD4+. TCD8+. Macrófagos. Leishmania (Leishmania) infantum chagasi.

\begin{abstract}
Visceral leishmaniasis in dogs is described as a chronic disease whose main symptoms are progressive weigth loss, cachexy and dermatologic lesions. Recently, the disease has been associated to neurologic disorders. A total of 40 dogs with visceral leishmaniasis were divided into two groups. The first composed of dogs without neurological signs ( $\mathrm{n}=30$ ) and the second by dogs with neurological disorders $(n=10)$. Brain samples were collected, stored in $10 \%$ buffered formalin and subjected to immunohistochemical examination for amastigotes forms of Leishmania (Leishmania) infantum chagasi, CD3+, CD4+ and CD8+ T lymphocytes and macrophages. Imunnohistochemistry evaluation revealed no amastigote forms of the parasite. CD3+ T lymphocytes were present in 24/30 (80\%) dogs without neurological signs and in all dogs from the second group $(\mathrm{p}=0.0011)$. CD4+ and CD8+ were rarely observed, with CD4+ immunostaining in $10 / 40(25 \%)$ dogs, from which half of them had neurological disease $(p=0.0090)$. The presence of CD8+ was detected only in 4/10 (40\%) dogs from neurological group ( $\mathrm{p}=0.0021)$. Macrophages were detected in 38/40 (95\%) dogs, without significant differences between groups $(\mathrm{p}=0.7664)$.
\end{abstract}

Keywords: TCD3+. TCD4+. TCD8+. Macrophages. Leishmania (Leishmania) infantum chagasi.

\section{Introdução}

A leishmaniose visceral, também conhecida como Calazar, é uma doença de caráter crônico que afeta o homem e os animais, transmitida, nas Américas, pela Leishmania (Leishmania) infantum chagasi. A doença possui algumas características comuns em seres humanos e em cães. Os últimos apresentam uma
Correspondência para:

Tatianna Frate Schwardt

Departamento de Clínica, Cirurgia e Reprodução animal. Faculdade de

Medicina Veterinária. Universidade Estadual Paulista

Rua Clóvis Pestana, 793 Araçatuba, SP

CEP: 16050-680 Brazil

tel: +5536361420

e-mail: tatifrate@yahoo.com.br

Recebido: 06/09/11

Aprovado: 20/12/12 
extensa variedade de sintomas, dentre eles emagrecimento progressivo, linfoadenopatia periférica, hepatoesplenomegalia, anemia, lesões cutâneas, alterações renais e oftálmicas ${ }^{1,2}$. Poucos são os trabalhos que citam a ocorrência de envolvimento do sistema nervoso central em cães com leishmaniose visceral. Entre os sintomas neurológicos observados por Marcondes ${ }^{3}$, destaca-se a ocorrência de convulsões generalizadas, mioclonias, vocalização, anisocoria, midríase bilateral, paralisia de nervos cranianos, inclinação da cabeça, tetraparesia e tetraplegia. De acordo com a autora, de 21 cães infectados com presença de alterações neurológicas, em apenas quatro animais foram identificadas coinfecções por Babesia canis, Cryptococcus sp, Toxoplasma gondii ou Neospora caninum e pelo vírus da cinomose. Nos outros 17 animais, as alterações neurológicas pareciam ser decorrentes exclusivamente da infecção por L. (L.) infantum chagasi.

Mesmo na ausência de sintomas neurológicos, têm sido descritas alterações histopatológicas do sistema nervoso de cães acometidos pela doença. Dentre elas, cita-se a ocorrência de leptomeningite, coroidite, congestão vascular, infiltrado de células inflamatórias, gliose, satelitose, neuronofagia e degeneração neuronal ${ }^{4,5,6}$. Apesar desses achados, somente Nieto et al. ${ }^{5}$ e Viñuelas et al. ${ }^{7}$ foram capazes de identificar formas amastigotas de Leishmania sp. em células ependimárias, linfócitos e macrófagos do plexo coroide e em histiócitos nas meninges de cães acometidos pela doença. Em função dos escassos achados de formas amastigotas do parasita no tecido nervoso, sugere-se que o quadro neurológico seja decorrente de uma ação do sistema imune. Garcia-Alonso et al. ${ }^{4}$, avaliando a presença de IgG sérica e liquórica em 27 cães naturalmente infectados por Leishmania infantum com ausência de sinais neurológicos, constataram a presença de IgG liquórica em $48 \%$ dos mesmos. De acordo com os autores, a origem das imunoglobulinas presentes no liquor não está clara; entretanto, os mesmos sugerem que elas sejam provenientes de uma lesão da barreira hematoencefálica, uma vez que foram encontrados extensos depósitos de antígenos de leishmania e de imunoglobulinas nos espaços intersticiais e intravasculares do plexo coroide desses cães.

Lima et al. $^{8}$, pesquisando anticorpos anti- L. (L.) infantum chagasi em 30 cães com leishmaniose visceral, dos quais três possuíam sintomas neurológicos, detectaram altos títulos de anticorpos séricos e liquóricos em todos os animais, sem correlação com a presença de sintomas neurológicos. Em outro estudo comparando cães naturalmente acometidos por leishmaniose visceral com e sem sintomas neurológicos foi detectada a presença de IgG anti- $L$. (L.) infantum chagasi em $68,8 \%(11 / 16)$ dos cães sem alterações neurológicas e em 27,3\% (3/11) dos cães com envolvimento neurológico. Os autores não verificaram uma correlação entre a presença de IgG no liquor e no soro de todos os animais, uma vez que alguns cães possuíam anticorpos liquóricos mas não séricos, sugerindo também uma produção intratecal de anticorpos e não só uma quebra da barreira hematoencefálica?

De acordo com Melo e Machado ${ }^{10}$, as alterações morfológicas no plexo coroide de cães com leishmaniose visceral promovem uma quebra da barreira hematoencefálica, aumentando a permeabilidade da mesma e permitindo a passagem de células inflamatórias e anticorpos para o sistema nervoso central. $\mathrm{Na}$ tentativa de melhor compreender a etiopatogenia das lesões neurológicas, o presente estudo teve como objetivos pesquisar a presença de formas amastigotas de Leishmania (L.) infantum chagasi, linfócitos CD3+, CD4+, CD8+ e macrófagos no sistema nervoso central de cães naturalmente acometidos pela doença.

\section{Material e Método}

\section{Animais}

Para a realização do presente estudo foram utilizados 40 cães naturalmente acometidos por leishmaniose visceral, encaminhados ao Hospital Veterinário da 
Faculdade de Medicina Veterinária da Universidade Estadual Paulista - UNESP - Campus de Araçatuba. Os animais foram distribuídos de acordo com a presença ou não de sintomas neurológicos, de modo que foram compostos dois grupos, o primeiro constituído por 30 cães sem envolvimento neurológico (grupo controle) e o segundo constituído por 10 animais com sintomas neurológicos. Os cães com alterações neurológicas foram selecionados durante o período de janeiro de 2004 a dezembro de 2010, os outros 30 foram selecionados durante o ano de 2010. Todos os animais eram provenientes do município de Araçatuba, São Paulo, área endêmica para a doença.

Os animais foram selecionados após diagnóstico parasitológico da doença, baseado no achado de formas amastigotas do parasita em esfregaços obtidos por punção biópsia aspirativa de órgãos linfoides. Em seguida, foram submetidos a um exame físico dando-se especial atenção ao exame neurológico. Após colheita de sangue total para pesquisa de anticorpos séricos anti-Neospora caninum e anti-Toxoplasma gondii, os cães receberam uma pré-anestesia com acepromazina (Acepran 0,2\% - Univet SA Indústria Veterinária - São Paulo, SP), seguida de uma indução e manutenção anestésica com pentobarbital sódico (Hypnol 3\% - Fontoveter - Itapira, SP). Após este procedimento, com os cães ainda em plano anestésico, aplicava-se uma ampola de cloreto de potássio (Cloreto de potássio a 19,1\% - Darrow - Rio de Janeiro, RJ), por via intravenosa, em cumprimento ao Decreto n ${ }^{\circ} .51 .838$ do Senado Federal, de 14 de março de 1963, o qual estabelece que animais domésticos portadores de leishmaniose devem ser submetidos à eutanásia. Em seguida, os animais foram necropsiados e colheu-se o encéfalo para realização de reação de imunoistoquímica.

\section{Reação de Imunoistoquímica}

Todos os cães foram necropsiados pela técnica empregada rotineiramente no Serviço de Patologia da Faculdade de Medicina Veterinária, UNESP, Campus de Araçatuba, realizando-se o exame externo do cadáver, evisceração e exame detalhado das alterações macroscópicas presentes nos órgãos. $\mathrm{O}$ encéfalo foi colhido inteiro e separado por um corte na fissura longitudinal do cérebro. Os hemisférios cerebrais foram fixados em formalina a $10 \%$ tamponada com fosfatos $\mathrm{pH}$ 7,2 e, após um período de aproximadamente 24 horas, colheu-se um fragmento do córtex frontal, lobo piriforme, plexo coroide do ventrículo lateral, mesencéfalo e cerebelo para inclusão em parafina. Os cortes foram confeccionados em lâminas silanizadas para análise imunoistoquímica e pesquisa de formas amastigotas de $L$. (L.) infantum chagasi, linfócitos T CD3+, CD4+, CD8+ e macrófagos. Para a realização das reações de imunoistoquímica, os cortes foram desparafinizados e hidratados, e a recuperação antigênica foi realizada com tratamento dos cortes em tampão EDTA para linfócitos CD8+ e tampão citrato para os demais antígenos. A detecção de linfócitos CD4+ e CD8+ foi realizada utilizado-se o kit CSA (Amplification Catalised System - K150011-Dako North America, INC- Via Real, CA) e os procedimentos foram seguidos de acordo com as indicações do kit. Para detecção de linfócitos T CD4+ e CD8+, utilizou-se o anticorpo monoclonal de camundongo.

Para a detecção de formas amastigotas de $L$. (L.) infantum chagasi, linfócitos CD3+ e macrófagos, os cortes foram incubados em peróxido de hidrogênio a $2 \%$ (10 volumes) para bloqueio da peroxidase endógena, seguido da incubação com leite desnatado 6\% em PBS 0,05\% para bloqueio de ligações inespecíficas. A pesquisa de formas amastigotas do parasita foi realizada utilizando-se um anticorpo primário anti-L. (L.) infantum chagasi (MHOM/ BR/72/cepa46), produzido em camundongo pelo Laboratório de Patologia de Moléstias Infecciosas do Departamento de Patologia da Faculdade de Medicina da USP, adsorvido com pó de sistema nervoso central de cão normal. Para detecção de linfócitos T CD3+, utilizou-se o anticorpo policlonal de coelho 
anti-CD3 humano (A0452- Dako North America, Inc- Via Real, CA); para a detecção de macrófagos, utilizou-se o anticorpo de rato anti-macrófago humano (MCA874G- AbD Serotec - Morphosys CoMunich, Germany). As lâminas foram então incubadas por 18 horas em câmara úmida. Após lavagem com solução tampão PBS e Tween 20 a 0,05\%, foram submetidas a nova incubação com anticorpo secundário biotinilado (K0690 - Dako North America, Inc. - Via Real, CA), novamente, submetidos à lavagem com tampão PBS e, posteriormente, incubadas com estreptavidina-peroxidase ( Kit LSAB - Dako North America, Inc. - Via Real, CA) a $37^{\circ} \mathrm{C}$, por mais 45 minutos. A reação final foi revelada com 3,3'-diaminobenzidina (DAB - Sigma Aldrich - St. Louis, MO), na presença de peróxido de hidrogênio $\left(\mathrm{H}_{2} \mathrm{O}_{2}\right)$.

A contra-coloração do tecido foi feita com hematoxilina de Harris. Após a desidratação dos cortes, as lâminas foram montadas com lamínulas, utilizando-se resina, e foram observadas em microscopia de luz convencional para avaliar a presença e a localização de formas amastigotas de leishmania e anticorpos. Como controle positivo das reações, foram utilizados cortes histológicos de tonsila palatina humana e de linfonodo canino. As imunomarcações foram analisadas de forma semi-quantitativa e classificadas comparativamente de acordo com a sua intensidade. A classificação foi definida em cruzes da seguinte forma: (-) ausente; (+) raras; (++) leve; (+++) moderada; $(++++)$ intensa. Para a realização da análise estatística, as cruzes foram substituídas por números de zero a quatro, e utilizou-se a somatória dos escores das cinco regiões encefálicas.

\section{Análise Estatística}

Para a comparação dos grupos foi utilizado o teste não paramétrico de Mann-Whitney, utilizando-se o programa SAS - Statistical Analysis System (1999). As análises foram consideradas significativas quando $\mathrm{p}<0,05$.

\section{Resultados}

Nenhum dos 40 animais avaliados apresentava definição racial, 25 (62,5\%) eram machos e 15 (37,5\%) fêmeas, e a idade dos mesmos variou entre um e oito anos, com uma media de cinco anos e meio. Doze cães do grupo controle (40\%) eram assintomáticos. Todos os outros animais incluídos no estudo eram sintomáticos, sendo que as alterações clínicas mais frequentemente observadas foram emagrecimento, caquexia, lesões cutâneas, hepato e esplenomegalia, linfoadenomegalia, palidez de mucosas e alterações oftálmicas. Os sintomas neurológicos observados incluíram convulsões generalizadas, locomoção atáxica, hipermetria, tremor de intenção, quedas e lesão em nervos cranianos. Alguns animais com sintomas neurológicos não apresentavam outras alterações ao exame físico. Vinte e quatro cães $(58,53 \%)$ possuíam anticorpos anti-N. caninum e $15(36,58 \%)$ anti-T. gondii. O título de anticorpos anti-N. caninum e anti- $T$. gondii dos animais com alterações neurológcias, bem como os sintomas de cada animal, apresentam-se listados no quadro 1. Em nenhum dos cortes histológicos dos 40 cães avaliados foram observados corpúsculos de inclusão do vírus da cinomose.

\section{Reação de imunoistoquímica para L. (L.) infantum chagasi}

Não foram identificadas formas amastigotas do parasita nos fragmentos encefálicos avaliados. No entanto, em 23/40 (57,5\%) animais foram observadas áreas de marcação antigênica no interior de vasos sanguíneos.

\section{Reação de imunoistoquímica para linfócitos CD3+}

Em 31/40 (77,5\%) cães foram observados linfócitos CD3+ no encéfalo (Figura 1a), variando em intensidade de acordo com o fragmento analisado. Todos os cães com sintomas neurológicos e $24 / 30$ (80\%) cães sem sinais de envolvimento neurológico apresentaram imunomarcação para CD3+. Destes, quatro não apresentavam sintomas evidentes da doença. Verifi- 


\begin{tabular}{|c|c|c|c|c|}
\hline CÃO & $\begin{array}{c}\text { Idade } \\
\text { (anos) }\end{array}$ & $\begin{array}{c}\text { RIFI } \\
\text { Toxo }\end{array}$ & $\begin{array}{c}\text { RIFI } \\
\text { Neo }\end{array}$ & SINTOMAS \\
\hline N1 & 1 & neg. & neg. & convulsões generalizadas \\
\hline N2 & 3 & neg. & $1: 100$ & convulsões generalizadas \\
\hline N3 & 5 & $1: 256$ & $1: 3200$ & locomoção atáxica, espasticidade de membros, hipermetria \\
\hline N4 & 3 & neg. & neg. & locomoção atáxica \\
\hline N5 & 2 & neg. & neg. & incapacidade para movimentação da mandíbula, tremor de intenção \\
\hline N6 & 1 & neg. & neg. & tetraparesia, nistagmo, estrabismo posicional, ceratoconjuntivite seca \\
\hline N7 & 1 & neg. & neg. & convulsões generalizadas, paresia de membros pélvicos \\
\hline N8 & 1 & neg. & neg. & locomoção atáxica \\
\hline N9 & 4 & neg. & neg. & locomoção ataxica, quedas, midríase bilateral, alopecia periocular \\
\hline N10 & 3 & neg. & neg. & inclinação de cabeça, andar em círculos para a direita \\
\hline
\end{tabular}

Quadro 1 - Idade, título de anticorpos anti-Toxoplasma gondii (RIFI Toxo) e anti-Neospora caninum (RIFI Neo) e alterações clínicas observados em 10 cães sem raça definida, naturalmente acometidos por leishmaniose visceral com sintomas neurológicos (grupo neurológico) (neg. - negativo)

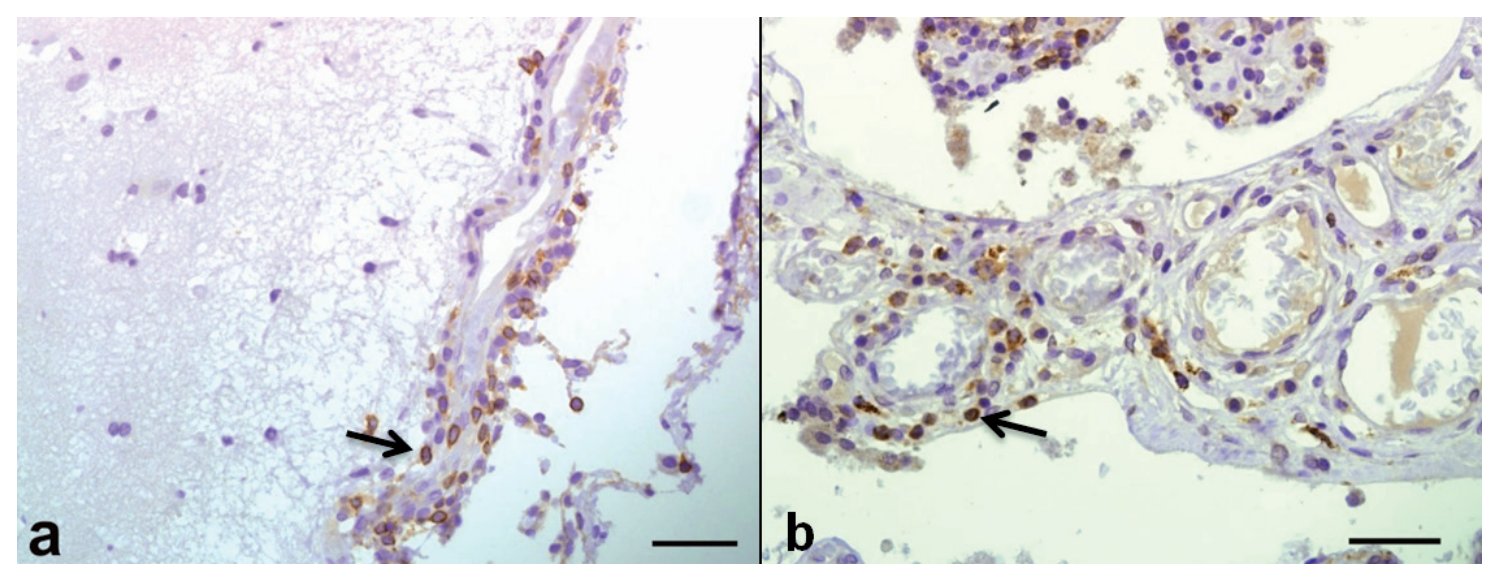

Figura 1 - Fotomicrografias de encéfalo de cães infectados por L.(L.) infantum chagasi. (a) Linfócitos CD3+ (seta) em região de meninges, visualizados através do método de imunohistoquímica- LSAB; (b) macrófagos (seta) em plexo coroide de ventrículo lateral, visualizados através do método de imunohistoquímica- LSAB. Barra: $50 \mu \mathrm{m}$

cou-se uma diferença estatisticamente significativa $(\mathrm{p}=0,0011)$ entre as imunomarcações do grupo controle e dos cães com sintomas neurológicos (Tabela 1). Os últimos apresentaram maior intensidade de marcação antigênica quando comparado ao grupo sem sintomas neurológicos; no entanto, na maior parte dos animais a marcação antigênica variou de rara $(+)$ a moderada $(+++)$. As regiões que mais apresentaram imunomarcação para $\mathrm{CD} 3$ + foram o lobo frontal, o mesencéfalo e o cerebelo, independente do tipo de sintoma neurológico apresentado pelos animais.

\section{Reação de imunoistoquímica para linfócitos CD4+}

Em 10/40 (25\%) cães foram observados linfócitos CD4+, sendo a marcação antigênica mais evidente no grupo de cães com sintomas neurológicos $(\mathrm{p}=0,0090)$. Dos animais com quadro neurológico 5/10 (50\%) apresentaram imunomarcações (Tabela 1). A marcação variou de leve $(+)$ a intensa $(++++)$, e as regiões que mais apresentaram CD4+ foram o plexo coroide e o mesencéfalo.

\section{Reação de imunoistoquímica para linfócitos CD8+}

Dos 40 cães analisados, apenas quatro apresentaram marcação antigênica para linfócitos $\mathrm{CD} 8+$, sendo todos com sintomas neurológicos $(\mathrm{p}=0,021)$ (Tabela 1). A marcação antigênica variou em intensidade de acordo com a região analisada. Um animal apresentou raros linfócitos CD8+ em região de cerebelo, dois animais apresentaram marcação moderada em região 
Tabela 1 - Mediana (Md), valor mínimo (Min) e máximo (Max) da soma dos escores utilizados para determinar a imunomarcação para linfócitos CD3+, CD4+, CD8+ e macrófagos (MO) no encéfalo de 40 cães naturalmente acometidos por leishmaniose visceral, sem (controle) e com (neurológico) presença de sintomas neurológicos

\begin{tabular}{cccccc}
\hline \multirow{2}{*}{ Marcadores } & \multicolumn{2}{c}{ Controle $(\mathrm{n}=30)$} & \multicolumn{2}{c}{ Neurológico $(\mathrm{n}=10)$} & \multirow{2}{*}{$\mathrm{p}^{(1)}$} \\
\cline { 2 - 5 } & Md & Min - Máx & Md & Min-Máx & \\
\hline CD3+ & 2 & $0-9$ & 7 & $3-11$ & 0,0011 \\
CD4+ & 0 & $0-4$ & 1 & $0-7$ & 0,0090 \\
CD8+ & 0 & $0-0$ & 0 & $0-4$ & 0,0021 \\
MO & 2 & $0-8$ & 3 & $0-12$ & 0,7664 \\
\hline
\end{tabular}

(1) Teste de Mann-Whitney

de córtex frontal e um único cão apresentou marcação intensa em região de lobo piriforme.

\section{Reação de imunoistoquímica para macrófagos}

Em 38/40 (95\%) cães estudados foram observados macrófagos (Figura 1b) no sistema nervoso central, principalmente em região de plexo coroide. Não foi verificada diferença estatisticamente significativa entre os grupos $(\mathrm{p}=0,7664)$ (Tabela 1$)$. Na maior parte dos animais, a marcação antigênica variou de rara $(+)$ a leve $(++)$.

\section{Discussão e Conclusões}

Embora a leishmaniose visceral canina seja uma doença sistêmica crônica, a literatura a respeito de animais com comprometimento neurológico é escassa. De 215 cães naturalmente acometidos por leishmaniose visceral avaliados clinicamente em Araçatuba-SP, área endêmica para a doença, $4 \%$ apresentaram sintomas neurológicos ${ }^{11}$. Os sintomas neurológicos observados nos cães do presente estudo foram semelhantes aos descritos por Marcondes ${ }^{3}$ e José-Lopez, De La Fuente e Añor ${ }^{12}$. Os últimos autores descreveram a ocorrência de alterações neurológicas de evolução aguda em dois cães com leishmaniose visceral, que apresentaram melhora após um mês da instituição do tratamento para a doença. A observação de animais com sinais de comprometimento neurológico restrito a algumas regiões encefálicas, tal como o que ocorreu em dois cães cujos sintomas evidenciavam uma lesão em tronco encefálico e cerebelo (N5) e no sistema vestibular central do lado direito (N10), dificultam o diagnóstico da doença. Nos dois animais a avaliação histopatológica do encéfalo identificou a presença de um infiltrado perivascular linfoplasmocitário, satelitose e neuronofagia, sem observação de cistos ou lesões localizadas nas áreas acometidas, compatíveis com a ocorrência de um acidente vascular cerebral, uma neoplasia ou meningoencefalite granulomatosa, distúrbios que foram considerados também quando da elaboração do diagnóstico diferencial, apesar da idade dos cães. Os sintomas evidenciados nos animais do presente estudo e relatados por outros autores ${ }^{3,11,12}$ chamam a atenção para a necessidade de inclusão da leishmaniose visceral entre as possíveis causas de problemas neurológicos, principalmente em cães vivendo em áreas endêmicas para a doença.

Somente dois cães com sintomas neurológicos possuíam títulos de anticorpos anti-T. gondii (N3) e anti-N. caninum (N2 e N3), agentes que têm sido observados em associação com infecções por $L$. (L.) infantum chagasi em áreas endêmicas ${ }^{13}$. No entanto, o exame histopatológico do sistema nervoso central não evidenciou a presença de cistos dos parasitas. Nos animais do presente estudo houve uma maior proporção de cães com título de anticorpos anti- $N$. caninum (58,53\%) quando comparado aos cães com anticorpos anti-T. gondii (36,58\%), divergindo dos achados de Gennari et al. ${ }^{13}$ que verificaram $32,6 \%$ de sororeatividade para neosporose e $41 \%$ para toxoplas- 
mose em cães com leishmaniose visceral provenientes da mesma área endêmica. Apesar destes resultados, não é possível creditar a esses agentes infecciosos as alterações observadas no sistema nervoso dos cães do presente estudo, uma vez que oito (80\%) cães com alterações neurológicas não possuíam anticorpos séricos contra esses parasitas. Nestes, também não foram observados corpúsculos de inclusão do vírus da cinomose nos cortes histológicos encefálicos, sugerindo a ausência de participação deste agente infeccioso no desenvolvimento das alterações neurológicas.

Apesar de não terem sido identificadas formas amastigotas do parasita no encéfalo dos cães, corroborando os resultados de estudos anteriores realizados por Marcondes ${ }^{3}$, não é possível excluir a participação do parasita na etiopatogenia das lesões, uma vez que outros estudos identificaram o mesmo no tecido nervoso ${ }^{5,7}$. Os resultados de estudos pretéritos ${ }^{4,8,9,10}$ também sugerem que o parasita penetra no tecido nervoso, uma vez que foram identificados anticorpos anti-Leishmania no liquor de cães com leishmaniose visceral, inclusive em quantidades superiores às dos anticorpos séricos ${ }^{8}$, sugerindo uma produção local e não só uma quebra da barreira hematencefálica. Gonçalves et al. ${ }^{14}$ identificaram o DNA do parasita no líquido cefalorraquidiano de cães naturalmente acometidos pela doença, sugerindo que há passagem de parasitas ou fragmentos destes pela barreira hematoliquórica. Mais recentemente, Márquez et al. ${ }^{15}$ descreveram a presença de Leishmania infantum no liquor, nervos espinhais, medula espinhal, parênquima cerebral e plexos coroides de um cão que apresentava quadro de tetraplegia, depressão e ausência de reflexos posturais.

Entretanto, a ausência do parasita no encéfalo de alguns cães sugere também a participação do sistema imune na patogenia do quadro neurológico. Cães que desenvolvem alterações clínicas decorrentes de leishmaniose visceral possuem uma severa depressão da função de células $T$ e uma elevação nos títulos de anticorpos séricos, demonstrando uma falha da imunidade celular e aumento da imunidade humoral11. Nos animais do presente estudo, foram detectadas diferenças significativas entre animais do grupo controle e do grupo neurológico no que tange a presença de linfócitos $\mathrm{CD} 3+(\mathrm{p}=0,0011)$, com evidente aumento de marcação no segundo grupo (Tabela 1), sugerindo a participação dessas células na patogenia da doença no sistema nervoso central. Apesar das diferenças observadas entre os grupos, verificou-se que $80 \%$ dos cães sem sintomas neurológicos também apresentavam imunomarcação para CD3+, confirmando as observações de Melo e Machado16, que verificaram um maior número de células CD3+ no encéfalo de cães com leishmaniose visceral sem sintomas neurológicos em relação a animais não infectados16. Tais achados diferem das observações de Marcondes3 que, ao avaliar 39 cães com leishmaniose visceral, dos quais 21 possuíam sintomas neurológicos, verificou marcação de células CD3+ semelhante nos animais de ambos os grupos.

Os cães com sintomas neurológicos apresentaram linfócitos CD3+ em lobo frontal, mesencéfalo e cerebelo, com raras células identificadas no plexo coroide. Apesar de estudos anteriores terem identificado a presença de intenso infiltrado inflamatório e marcação para linfócitos T CD3+ na região do plexo coroide de cães portadores de leishmaniose visceral sem quadro neurológico ${ }^{10,17}$, nenhum dos animais avaliados nestes estudos possuía sintomas neurológicos. É provável que a resposta inflamatória nesta região seja dependente do tempo de evolução da doença. Somente células $\mathrm{T}$ ativadas penetram no tecido nervoso ${ }^{16} \mathrm{e}$, de acordo com Melo e Machado ${ }^{10}$ e Melo et al. ${ }^{17}$, o plexo coroide deve ser o local de entrada destas células. A presença de sintomas neurológicos nos cães do presente estudo sugere um maior tempo de evolução da doença a nível encefálico, uma vez que estes aparecem com o agravamento das alterações histopatológicas. Deste modo, é provável que haja uma presença maior 
de células CD3+ no plexo coroide no início do processo inflamatório do sistema nervoso central e que, com a evolução da doença estas células se dispersem para outros locais no encéfalo.

Apesar de linfócitos CD3+ terem sido encontrados em todos os cães com sintomas neurológicos, o mesmo não aconteceu com linfócitos T CD4+ e CD8+, sugerindo a participação de células CD3+CD4-CD8-, tais como as NK (natural killer), linfócitos TCD3+ $\alpha \beta$ ou $\mathrm{TCD} 3+\gamma \delta$, na patogenia das lesões. As células NK, além de possuírem a capacidade de lisar células infectadas, podem modular a resposta imune por meio da secreção de citocinas pró-inflamatórias e da interação com células apresentadoras de antígenos ${ }^{18,19}$. Além das células NK, foi identificado por citometria de fluxo um grupo heterogêneo de linfócitos $\mathrm{T}$ que expressa marcadores NK e T, conhecido como células TNK. Estas células produzem citocinas rapidamente e, dessa forma, influenciam diversas respostas imunes e processos patogênicos. Apesar de já terem sido identificados fatores que promovem seu desenvolvimento, mecanismos de regulação da produção de suas citocinas, e como estas células podem influenciar células dendríticas e outros tipos celulares, o conhecimento de antígenos naturais reconhecidos pelas células TNK e seu papel fisiológico ainda permanecem incertos. A ativação destas células pode levar tanto a supressão quanto a estimulação da resposta imune. Possivelmente existem subclasses de células TNK, na dependência do local anatômico e do fenótipo da superfície celular, cuja ativação leva a respostas distintas. Outra possibilidade é de que a qualidade do sinal no receptor celular influencie no padrão de citocinas produzidas $^{20}$. Estas células já foram implicadas na resposta imune a infecção por Leishmania ${ }^{19,21}$.

Linfócitos TCD3+aß e TCD3+ $\gamma \delta$ também já foram implicados na patogenia da leishmaniose visceral e cutânea em humanos ${ }^{22}$. Antonelli et $\mathrm{al}^{23}$, verificaram que $75 \%$ das células T CD4-CD8- na circulação de pacientes com leishmaniose cutânea expressavam receptores $\alpha ß$, enquanto as outras expressavam receptores $\gamma \delta$. Em contraste, em indivíduos não infectados a relação é oposta, com apenas $20 \%$ de expressão de receptores $\alpha ß$. Linfócitos TCD $3+\gamma \delta$ também encontram-se significantemente aumentadas na circulação de pacientes com leishmaniose visceral, indicando que devem possuir um importante papel na resposta imune primária ao parasita ${ }^{24,25}$. Estas células secretam altos níveis de fator de crescimento e de fator de diferenciação de linfócitos $\mathrm{B}$, importantes no desenvolvimento da resposta imune humoral, levando a produção de imunoglobulinas, que agravam o quadro de leishmaniose visceral ${ }^{24}$.

Em 10/40 (25\%) animais foram observados linfócitos $\mathrm{CD} 4+$, mais evidente no grupo de cães com sintomas neurológicos, e somente quatro (10\%) cães com sintomas neurológicos apresentaram marcação antigênica para linfócitos CD8+. Cães naturalmente infectados por L. infantum apresentam uma redução nas populações de CD4+ e CD8+, que são restauradas após o tratamento ${ }^{26}$. Não existem estudos na literatura compilada que tenham investigado a participação dessa classe de linfócitos no sistema nervoso central de indivíduos acometidos por leishmaniose visceral, seja canina ou humana. No entanto, estudos realizados no tecido renal de cães naturalmente acometidos pela doença evidenciaram a presença de linfócitos T CD4+ e T CD8+ em quatro e em apenas um, de seis animais avaliados, respectivamente ${ }^{27}$. Linfócitos CD8+ parecem estar envolvidos com o controle da infecção na leishmaniose visceral, uma vez que foram detectados em cães assintomáticos experimentalmente infectados com Leishmania infantum, mas não foram observados em animais sintomáticos, sugerindo que a lise de macrófagos infectados por linfócitos $\mathrm{T}$ citotóxicos representa um mecanismo adicional no combate ao parasita ${ }^{28}$. Esse fato poderia explicar o pequeno número de animais com imunomarcação para estas células no presente estudo, já que todos os cães apresentavam sintomas da doença. No entanto, novos 
estudos devem ser conduzidos para elucidar porque estas células estavam presentes em pequeno número apenas em animais com sintomas neurológicos e, portanto, com um quadro mais acentuado de lesões encefálicas.

Foram observadas marcações antigênicas para macrófagos nos animais dos dois grupos, principalmente no plexo coroide, demonstrando a participação destas células na patogenia da doença independente da presença do quadro neurológico, e corroborando os achados de Marcondes ${ }^{3}$ que, no entanto, encontrou uma maior marcação em cães com sintomas neurológicos. A barreira hematoliquórica, presente no plexo coroide, bloqueia a passagem de substâncias do sangue para o liquor. Estudos anteriores demonstraram que esta barreira encontra-se rompida e que o plexo

\section{Referências}

1. CIARAMELLA, P.; CORONA, M. Canine Leishmaniasis: Clinical and diagnostic aspects. Compendium on Continuing Education for the Practicing Veterinarian, v. 25, n. 5, p. 358368, 2003.

2. MARCONDES, M. Leishmaniose uma zoonose. In: CONGRESSO PAULISTA DE CLÍNICOS VETERINÁRIOS DE PEQUENOS ANIMAIS, 7., 2007, São Paulo, São Paulo, Anais... São Paulo: ANCLIVEPA, 2007. p. 211.

3. MARCONDES, M. Envolvimento do sistema nervoso central na leishmaniose visceral canina. 2009. $154 \mathrm{f}$. Tese (Livre-docência) - Faculdade de Odontologia. Universidade Estadual Paulista, Araçatuba, 2008.

4. GARCÍA-ALONSO, M.; NIETO, A. G.; BLANCO, A.; REQUENA, J. M.; ALONSO, C.; NAVARRETE, I. Presence of antibodies in the aqueous humour and cerebrospinal fluid during Leishmania infections in dogs. Pathological features at the central nervous system. Parasite Immunology, v. 18, n. 11, p. 539-546, 1996.

5. NIETO, C. G.; VIÑUELAS, I.; BLANCO, A.; GARCÍAALONSO, M.; VERDUGO, S. G.; NAVARRETE, I. Detection of Leishmania infantum amastigotes in canine choroid plexus. Veterinary Record, v. 139, n. 14, p. 346-347, 1996.

6. IKEDA, F. A.; LAURENTI, M. D.; CORBETT, C. E.; FEITOSA, M. M.; MACHADO, G. F.; PERRI, S. H. V. Histological and immunohistochemical study of the central nervous system of dogs naturally infected by Leishmania chagasi. Brazilian Journal of Veterinary Research and Animal Science, v. 44, n. 1 , p. $5-11,2007$

7. VIÑUELAS, J.; GARCÍA-ALONSO, M.; FERRANDO, L.; NAVARRETE, I.; MOLANO, I.; MIRÓN, C.; CARCELÉN, J.; ALONSO, C.; NIETO, C. G. Meningeal leishmaniosis induced by Leishmania infantum in naturally infected dogs. Veterinary Parasitology, v. 101, n. 1, p. 23-27, 2001

8. LIMA, V. M. F; GONCALVES, M. E.; IKEDA, F. A.; LUVIZOTTO, M. C. R.; FEITOSA, M. M. Anti-leishmania coroide age como a via de início do processo inflamatório no sistema nervoso central de cães com leishmaniose visceral ${ }^{10,17,29}$. Apesar de não ter sido identificada a presença de formas amastigotas do parasita no encéfalo dos cães do presente estudo, antígenos solúveis ou outras proteínas podem ter mediado eventos inflamatórios intravasculares, conforme salientado por Melo e Machado ${ }^{16}$.

Baseando-se nos resultados do presente estudo, é possível concluir que as alterações neurológicas associadas à leishmaniose visceral canina não são dependentes da presença do parasita no tecido nervoso e devem estar relacionadas a um mecanismo imunomediado. No entanto, novos estudos precisam ser realizados para identificar outros tipos celulares envolvidos na patogênese das lesões.

antibodies in cerebrospinal fluid from dogs with visceral leishmaniasis. Brazilian Journal of Medical and Biological Research, v. 36, n. 4, p. 485-489, 2003.

9. FEITOSA, M. M.; IKEDA, F. A.; BONELLO, F. L.; CIARLINI, P. C.; GONCALVES, M. E.; LIMA, V. M. F.; PERRI, S. H. V. Avaliação liquórica de cães, com e sem sintomatologia neurológica naturalmente acometidos por leishmaniose visceral. Veterinária Notícias, v. 11, n. 2, p. 61-69, 2005.

10.MELO, G. D.; MACHADO, G. F. Choroid plexus involvment in dogs with spontaneous visceral leishmaniasis: a histopathological investigation. Brazilian Journal of Veterinary Pathology, v. 2, p. 69-74, 2009.

11.FEITOSA, M. M.; IKEDA, F. A.; LUVIZOTTO, M. C. R.; PERRI, S. H. V. Aspectos clínicos de cães com leishmaniose visceral no município de Araçatuba - São Paulo (Brasil). Clínica Veterinária, v. 5, n. 28, p. 36-44, 2000.

12.JOSÉ-LOPEZ, R.; LA FUENTE, C. de; AÑOR, S. Presumed brain infarctions in two dogs with systemic leishmaniasis. Journal of Small Animal Practice, v. 53, n. 9, p. 554-557, 2012.

13. GENNARI, S. M.; FRANCO, W. A. C.; FEITOSA, M. M.; IKEDA, F. A.; LIMA, V. M. F.; AMAKU, M. Presence of antiNeospora caninum and Toxoplasma gondii antibodies in dogs with visceral leishmaniosis from the region of Araçatuba, São Paulo, Brazil. Brazilian Journal of Veterinary Research and Animal Science, v. 43, n. 5, p. 613-619, 2006.

14.GONCALVEZ, M. E.; PEREIRA, F. V.; DIAS, A. K. K.; IRIKURAS, S.; NUNES, C. M.; MARCONDES, M. Detecção de DNA de leishmania sp em líquor de cães procedentes de área endẽmica para leishmaniose visceral canina. In: CONGRESSO BRASILEIRO DE PARASITOLOGOIA VETERINARIA, 13.; SIMPÓSIO LATINO AMERCICANO DE RICKETSIAS, 2004, Ouro Preto, Anais... Jaboticabal: CBPV, 2004.

15. MÁRQUEZ, M.; PEDREGOSA, J. R.; LÓPEZ, J.; MARCOSALAZAR, P.; FONDEVILA, D.; PUMAROLA, M. Leishmania amastigotes in the central nervous system of a naturally 
infected dog. Journal of Veterinary Diagnostic Investigation, v. 24, n. 4, p. 1234-1239, 2012.

16. MELO, G. D.; MACHADO, G. F. Glial reactivity in dogs with visceral leishmaniasis: correlation with $\mathrm{T}$ lymphocyte infiltration and with cerebrospinal fluid anti-Leishmania antibody titres. Cell and Tissue Research, v. 346, n. 3, p. $293-$ 304, 2011.

17.MELO, G. D.; MARCONDES, M.; VASCONCELOS, R. O.; MACHADO, G. F. Leukocyte entry into de CNS of Leishmanixa chagasi naturally infected dogs. Veterinary Parasitology, v. 162 , n. $3 / 4$, p. $248-256,2009$.

18.GAO, B.; RADAEVA, S.; PARK, O. Liver natural killer and natural killer $\mathrm{T}$ cells: immunobiology and emerging roles in liver diseases. Journal of Leukocyte Biology, v. 86, n. 3, p. 513-528, 2009.

19.BOGDAN, C. Natural killer cells in experimental and human leishmaniasis. Cellular and Infection Microbiology, v. 2, p. $1-9,2012$.

20.KRONENBERG, M. Toward an understanding of NKT cell biology: progress and paradoxes. Annual Review of Immunology, v, 23, p. 877-900, 2005.

21. AMPREY, J. L.; IM, J. S.; TURCO, S. J.; MURRAY, H. W.; ILLARIONOV, P. A.; BESRA, G. S.; PORCELLI, S. A.; SPATH, G. F. A subset of liver NK T cells is activated during Leishmania donovani infection by CD1d-bound lipophosphoglycan. The Journal of Experimental Medicine, v. 200, n. 7, p. 895-904, 2004.

22.GOLLOB, K. J.; ANTONELLI, L. R. V.; FARIA, D. R.; KEESEN, T. S. L.; DUTRA, W. O. Immunoregulatory mechanisms and CD4-CD8- (double negative) T cell subpopulations in human cutaneous leishmaniasis: a balancing act between protection and pathology. International Immunopharmacology, v. 8, n. 10, p. 1338-1343, 2008.

23. ANTONELLI, L. R.; DUTRA, W. O.; OLIVEIRA, R. R.; TORRES, K. C.; GUIMARÃES, L. H.; BACELLAR, O.;
GOLLOB, H. J. Disparate immunoregulatory potentials for double-negative (CD4- CD8-) alpha beta and gamma delta $\mathrm{T}$ cells from human patients with cutaneous leishmaniasis. Infection and Immunity, v. 74, n. 11, p. 6317-623, 2006.

24. RAZIUDDIN, S.; TELMANASI, A. W.; EL-AWAD, M. E.; ALAMAURI, O.; AL-JANADI, M. Gamma-delta T cells and the immune response in visceral leishmaniasis. Europe Journal of Imunnology, v. 22, n. 5, p. 1143-1148, 1992.

25.RUSSO, D. M.; ARMITAGE, R. J.; BARRAL-NETO, M.; BARRAL, A.; GRABSTEIN, K. H.; REEED, S. G. Antigenreactive gamma-delta $T$ cell in human leishmaniasis. Journal of Immunology, v. 151, n. 7, p. 3712-3718, 1993.

26.BOURDOISEAU, G.; BONNEFONT, C.; HOAREAU, E.; BOEHRINGER, C.; STOLLE, T.; CHABANNE, L. Specific IgG1 and IgG2 antibody and lymphocyte subset levels in naturally Leishmania infantum-infected treated and untreated dogs. Veterinary Immunology and Immunopathology, v. 59, n. 1/2, p. 21-30, 1997.

27. COSTA, F. A.; GUERRA, J. L.; SILVA, S. M.; KLEIN, R. P.; MENDONÇA, I. L.; GOTO, H. CD4 (+) T cells participate in the nephropathy of canine visceral leishmaniasis. Brazilian Journal of Medical and Biologic Research, v. 33, n. 12, p. $1455-1458,2000$.

28. PINELLI, E.; GONZALO, R. M.; BOOG, C. J. P.; RUTTEN, V.; GEBHARD, D.; DEL REAL, G.; RUITENBERG, E. J. Leishmania infantum-specific $\mathrm{T}$ cell lines derived from asymptomatic dogs that lyse infected macrophages in a major histocompatibility complex-restricted manner. European Journal of Immunology, v. 25, n. 6, p. 1594-1600, 1995.

29. MACHADO, G. F.; MELO, G. D.; MORAES, O. C.; SOUZA, M. S.; MARCONDES, M.; PERRI, S. H.; VASCONCELOS, R. O. Differential alterations in the activity of matrix metalloproteinases within the nervous tissue of dogs in distinct manifestations of visceral leishmaniasis. Veterinary Immunology and Immunopathology, v. 136, n. 3/4, p. 340345,2010 . 